\title{
A comparison between anamnestic, rhinomanometric and radiological methods of diagnosing mouth-
} breathing

\author{
Urs Thüer, Robert Kuster and Bengt Ingervall \\ Orthodontic Clinic, University of Bern, Switzerland
}

SUMMARY Three methods of evaluating the mode of breathing were applied in 119 children aged 7-15 years who were to start orthodontic treatment for various malocclusions. The three methods were: the history, rhinomanometric recording of the nasal airflow and determination of the size of the airway on profile and frontal cephalograms. The variables describing the mode of breathing were correlated with the facial morphology and the natural position of the head and the cervical spine as recorded with profile cephalometry.

There were no correlations between the results of the evaluation of the mode of breathing obtained with the three methods. Nor were there any correlations between these and the position of the head or the cervical spine. A history of mouth-breathing, the rhinomanometrically determined airflow through the nose and the size of the airway on the profile cephalogram were, however, correlated with the long face morphology characteristic of mouth-breathing.

A diagnosis of mouth-breathing should be based on different supplementary methods, the history and the size of the airway on the profile cephalogram being at least as valuable as the rhinomanometric recording.

\section{Introduction}

Habitual mouth-breathing is an aetiological factor for malocclusion (Linder-Aronson 1970). The mechanism is thought to be a deviation from the normal of the forces from the soft tissues acting on the teeth. Mouth-breathing is thus associated with extension of the head (Solow and Greve 1979, Woodside and LinderAronson 1979, Wenzel et al. 1983) whereby the circumoral soft tissues and the tissues of the neck may be stretched (Solow and Kreiborg 1977) with an increased pressure from these tissues on the teeth (Hellsing and L'Estrange 1987, Ingervall and Thüer 1988). Another effect of mouth-breathing, however, is lowering of the position of the mandible and the tongue, with decreased pressure from the tongue on the teeth (Archer and Vig 1985).

Besides being of interest as an aetiological factor for malocclusion, mouth-breathing also hinders the use of bimaxillary functional orthodontic appliances because these obstruct the airflow through the mouth. It is therefore important to try to evaluate the mode of breathing of the patient at the orthodontic examination. An important diagnostic aid is the anamnestic part of the examination. Rhinomanometric examination of the nasal resistance to breathing has been used as a research method (LinderAronson 1970, Solow and Greve 1980) but, bèsides being fairly_complicated and rarely available in the clinical situation, this method tends to give large errors (Kuster et al. 1989). Standard orthodontic documentation by measuring the size of the airway on profile and frontal cephalograms has therefore been tried (Holmberg and Linder-Aronson 1979) but this method has been criticized as being unphysiological (Vig and Hall 1980).

The problem of diagnosing the mode of breathing without using sophisticated and elaborate methods (Gurley and Vig 1982, Warren et al. 1986, Keall and Vig 1987) is therefore unsolved. The present study was undertaken in order to elucidate further the relationships 
between anamnestic, rhinomanometric and radiographic methods of diagnosing the mode of breathing and between these methods and the facial morphology. The study further aims at establishing average values for the rhino-manometrically determined nasal resistance to breathing in children at the ages when orthodontic treatment is usually started.

\section{Subjects and methods}

All children that were to start treatment at the Orthodontic Clinic during the period in question were included in the study. The group therefore consists of children with varying types of malocclusion. In total, 119 children, 52 boys and 67 girls, aged 7 years, 2 months to 15 years, 6 months, were studied. The median age of the group was 10 years, 5 months (boys 9 years, 11 months; girls 11 years, 2 months). The age distribution is given in Table 3.

The following data were obtained from each child:

1. anamnestic data obtained by means of a questionnaire,

2. rhinomanometric recordings of nasal respiratory resistance,

3. cephalometric radiographs in the sagittal and frontal planes.

\section{Questionnaire}

The questionnaire contained five questions; one dealing with respiratory allergy, one asking whether the child had undergone adenoidectomy, one dealing with rhinitis at the time of the examination and two questions asked whether mouth-breathing was the rule in the day-time or during nights. As the child was usually accompanied by the mother, the questionnaire was as a rule filled in by her.

\section{Rhinomanometry}

The rhinomanometric recordings were made with a Rhinotest $\mu \mathrm{P}$ rhinomanometer (Electronic-Vertriebs-Gmbh, Ludwigshafen/Rhein). The rhinomanometer was used together with a storage screen oscilloscope (Tectronix $\mathrm{Co}$ ) and a paper printer. The oscilloscope allowed the child to observe the recorded pressure-flow curves (biofeedback) in order to master the technique of posterior rhinomanometry.

An Ambu breathing mask (Ambu Inter-

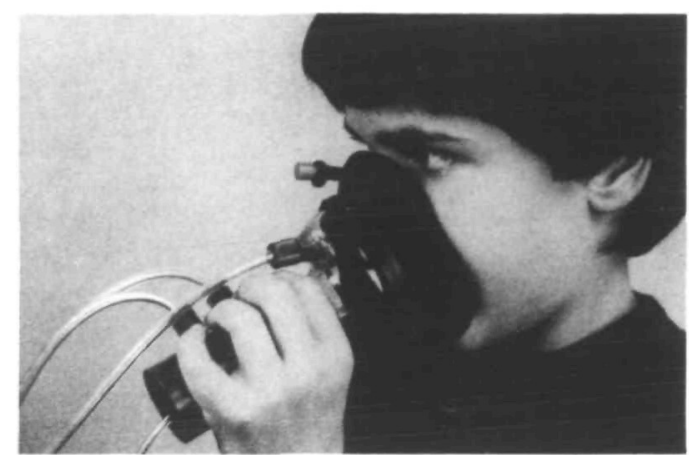

Figure 1 Rhinomanometric recording with the breathing mask.

national, Copenhagen), covering the nose and mouth, was used (Fig. 1). The flow through the nose in $\mathrm{cm}^{3} / \mathrm{sec}$ at a differential pressure of 150 $\mathrm{Pa}$ was recorded. To allow the measurement of the pressure difference between the air inside the breathing mask and the air in the oral cavity, a tube was passed through the flow-meter of the mask into the mouth. In order to prevent the tube from being occluded in the mouth, it was equipped with a plastic funnel at the end. This technique for performing posterior rhinomanometry, including the biofeedback, is in accordance with the method of Solow and Greve (1980) and has been described in detail, including the error of the method, by Kuster et al. (1989).

Eight rhinomanometric recordings were done, four before and four after decongestion of the nasal mucosa with Otrivine ${ }^{\circledR}$ drops. The mean value of the four recordings before and after decongestion, respectively, was used as a measure of the nasal resistance to breathing.

\section{Roentgencephalometry}

Profile cephalograms were taken with the child standing upright with the head in natural balance according to the technique of Siersbaek-Nielsen and Solow (1982) and with the mandible in the intercuspal occlusal position. The linear magnification was 3.3 per cent. The method used, including the errors of the method in the recording of natural head position, was described in detail by Kuster et al. (1989).

The profile cephalogram was used for the evaluation of the facial morphology utilizing the reference points and planes shown in Figure 2. The variables given in Table 1 were measured.

Variables 10 and 11 are the quotients between the posterior and anterior face heights and 


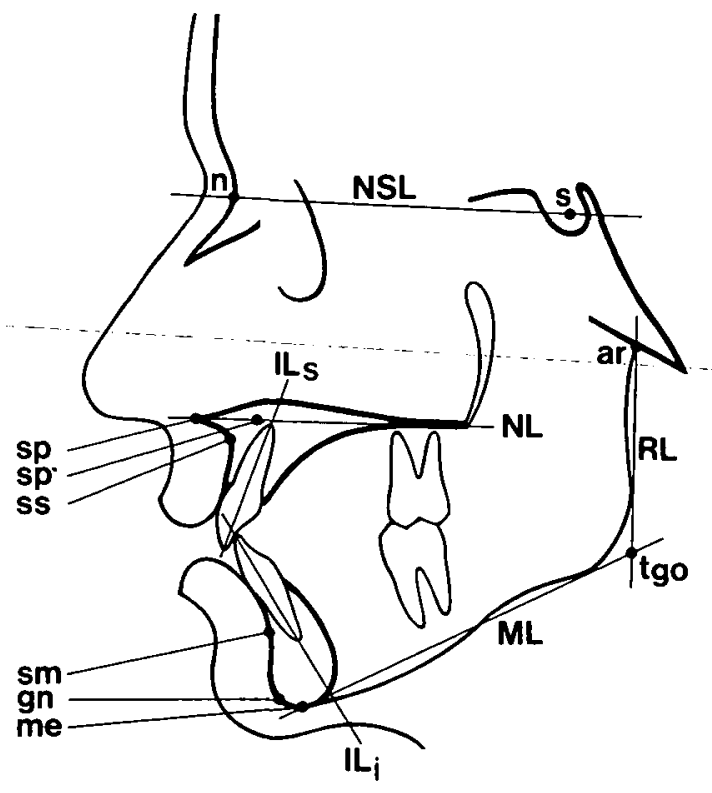

Figure 2 Reference points and lines used in the analysis of facial morphology.

Table 1 Variables measured on the profile cephalogram for the evaluation of facial morphology.

\begin{tabular}{|c|c|}
\hline 1. $n-s-a r^{\circ}$ & 8. $\mathrm{RL} / \mathrm{ML}^{\circ}$ \\
\hline 2. $s-n-s s^{\circ}$ & 9. $\mathrm{n}-\mathrm{s}-\mathrm{gn}{ }^{\circ}$ \\
\hline 3. $s-n-s m^{\circ}$ & 10. s-tgo: n-me \\
\hline 4. $s s-n-s m^{\circ}$ & 11. $\mathrm{n}-\mathrm{sp}^{\prime}: \mathrm{sp}^{\prime}-\mathrm{me}$ \\
\hline 5. $\mathrm{NSL} / \mathrm{NL}^{\circ}$ & 12. ILs/NL ${ }^{\circ}$ \\
\hline 6. $\mathrm{NSL} / \mathrm{ML}^{\circ}$ & 13. $\mathrm{IL}_{\mathrm{i}} / \mathrm{ML}^{\circ}$ \\
\hline 7. $\mathrm{NL} / \mathrm{ML}^{\circ}$ & 14. $\mathrm{IL}_{s} / \mathrm{IL}_{\mathrm{i}}{ }^{\circ}$ \\
\hline
\end{tabular}

between the upper and lower anterior face heights, respectively.

The profile cephalogrām was further-used to express the position of the head in relation to the true vertical (Variables NSL/VER ${ }^{\circ}, \mathrm{NL} \mathrm{VER}^{\circ}$, ML/VER ${ }^{\circ}$, Fig. 3) and to the cervical column (Var. NSL/OPT ${ }^{\circ}$, NSL/CVT ${ }^{\circ}$ ) as well as the cervical inclination (Var. OPT/HOR ${ }^{\circ}, \mathrm{CVT} /$ $\mathrm{HOR}^{\circ}$.

The size of the nasopharynx and the relative size of the adenoids were also measured on the profile cephalogram using the reference points shown in Figure 3. The definitions of these points are in accordance with Linder-Aronson and Henrikson (1973). The following variables were measured: pm-ba and pm-so, expressing the depth of the bony nasopharynx; pm-ad 1 and $\mathrm{pm}-\mathrm{ad}_{2}$, expressing the size of the airway space;

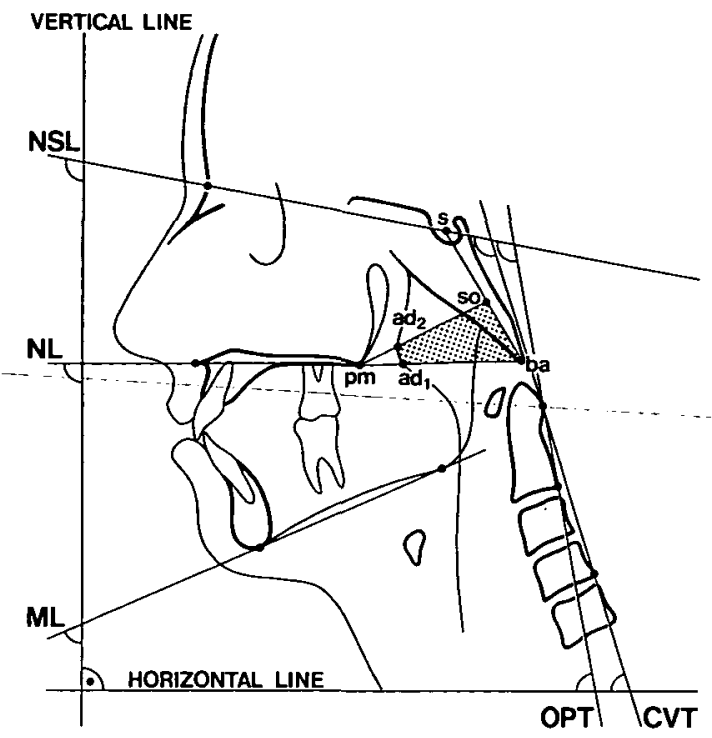

Figure 3 Reference points used in the analysis of the size of the pharynx and of the adenoids and reference lines used in the analysis of head position, cervical inclination and cranio-cervical relation.

$\mathrm{ad}_{1}$-ba and $\mathrm{ad}_{2}$-so, expressing the size of the adenoids; quotients $\mathrm{ad}_{1}$-ba: pm-ba and $\mathrm{ad}_{2}$ so: $\mathrm{pm}$-so, expressing the relative size of the adenoids in relation to the size of the nasopharynx; the size of the surface $\mathrm{ad}_{1}-\mathrm{ad}_{2}$-so-ba$\mathrm{ad}_{1}$ in relation to the size of the surface pmso-ba-pm expressing the relative size of the adenoids.

In the cephalometric analysis angles and distances were measured with the aid of a digitizing coordinate tracer (Gebauer 1977) and surfaces with a digitizing planimeter (MOP-AMO3, Kontron Messgeräte München).

The postero-anterior cephalogram_was taken with the head oriented with the Frankfort plane horizontal and had a linear magnification of 5 per cent for structures in the vertical plane through the porion. The width and height of the nasal cavity was measured on a tracing of the cephalogram according to Figure 4 . In addition, the size of the nasal air passage as judged from radiolucent zones on the radiograph (Fig. 4) was measured with the planimeter. The size of the nasal airway was also judged visually on the cephalogram using the scale of Holmberg and Linder-Aronson (1979). The scale has three grades: open nasal passage, partial nasal obstruction, and total nasal obstruction. This 


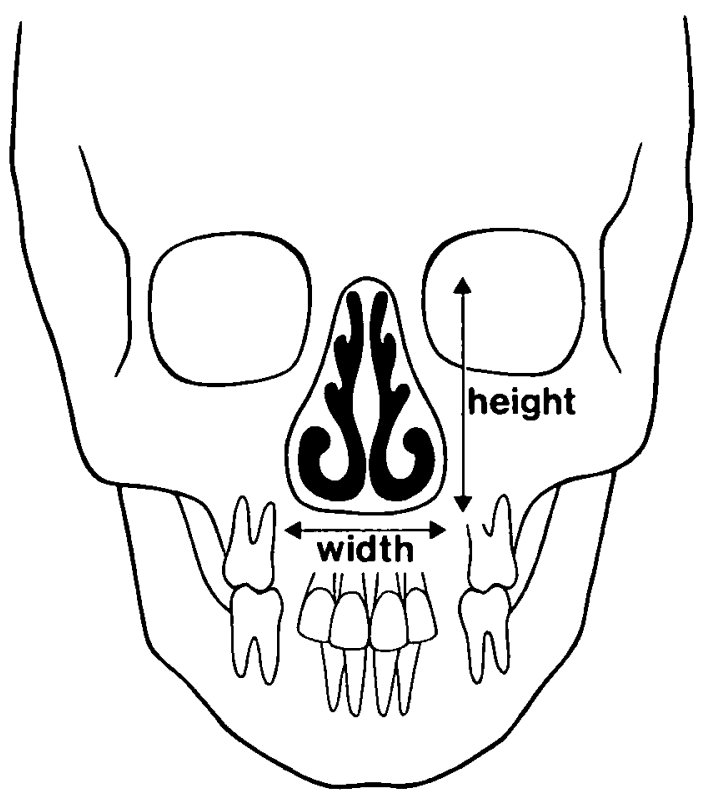

Figure 4 Measurements of width and height of the nasal cavity and size of the nasal air passage on the frontal cephalogram.

judgement was done independently by the three authors. The agreement of at least two observers was obtained in all cases and was recorded as the visual size of the nasal air passage.

\section{Statistical methods}

Sex-related differences and the relations among the anamnestic (questionnaire) variables and between these and other variables were tested with the $\chi^{2}$ test or Mann-Whitney's U-test. Rank correlation between continuous variables was calculated according to Spearman. For $n=119$ the critical values of the correlation coefficients are $0.18(0.01<\mathrm{P}<0.05), 0.24(0.001<\mathrm{P}<0.01)$ and $0.30(\mathrm{P}<0.001)$. Testing of distributions for skewness and kurtosis was done by calculation of $\sqrt{\mathrm{b} 1}$ and b2, respectively (Pearson and Hartley 1966).

\section{Results}

There were few significant sex differences in the recorded variables. A positive answer concerning respiratory allergy was more frequent in boys $(25 \%)$ than in girls $(10 \%)(0.01<P<0.05)$. The inclination of the cervical column (CVT/HOR) was greater in girls (mean 86.3) than in boys (mean 89.6) and the angle NSL/CVT was like- wise greater in girls (mean 100.8) than in boys (mean 96.2) $(0.001<P<0.01)$. Because few sex differences were found, the material was treated as one group in the subsequent analysis.

\section{Questionnaire}

Seven girls and 13 boys answered the question on respiratory allergy affirmatively. A history of allergy was thus noted in altogether 17 per cent of the children while 21 per cent said that they had undergone adenoidectomy. A history of rhinitis at the time of the examination was given by 27 per cent of the children. Twenty-six per cent of the children answered that they were mouth-breathers in the day-time and 34 per cent during the night.

\section{Nasal resistance to breathing}

The airflow through the nose and the nasal respiratory resistance measured by posterior rhinomanometry with and without decongested mucosa are given in Table 2.

Table 2 Airflow through the nose (in $\mathrm{cm}^{3} / \mathrm{sec}$ ) at a differential pressure of $150 \mathrm{~Pa}$ and nasal respiratory resistance (in $\mathrm{Pa} \mathrm{cm} / \mathrm{sec}$ ).

\begin{tabular}{|c|c|c|c|c|c|}
\hline & $\mathrm{n}$ & Mean & s.d. & Median & Range \\
\hline \multicolumn{6}{|l|}{ Air flow } \\
\hline Without nose-drops & 119 & 301 & 89 & 298 & $114-638$ \\
\hline With nose-drops & 115 & 403 & 115 & 394 & $137-849$ \\
\hline \multicolumn{6}{|c|}{ Resistance } \\
\hline Without nose drops & 119 & 0.55 & 0.20 & 0.51 & $0.10-1.32$ \\
\hline With nose drops & 115 & 0.41 & 0.15 & 0.38 & $0.17-1.10$ \\
\hline
\end{tabular}

The distributions for both airflow and resistance were significantly positively skewed and leptokurtic $(0.01<\mathrm{P}<0.05 \quad$ and $0.001<\mathrm{P}<0.01$ ).

There was no tendency for the rhinomanometric values to vary with sex, nor did the values recorded with nose-drops vary with age. There was, however, a significant positive correlation between airflow recorded without nosedrops and age (rho $=0.18$ ). The airflow values for children of different ages are given in Table 3.

\section{Relations between history and other variables}

There was a significant relation between allergy and the size of the nasal airway measured on the antero-posterior cephalogram $(0.01<\mathrm{P}<0.05)$. Children who had a history of allergy had 
Table 3 Airflow through the nose (in $\mathrm{cm}^{3} / \mathrm{sec}$ ) at $150 \mathrm{~Pa}$ in children of different age.

\begin{tabular}{|c|c|c|c|c|c|c|c|c|c|}
\hline \multirow{2}{*}{$\begin{array}{l}\text { Age } \\
\text { years }\end{array}$} & \multirow[b]{2}{*}{$\mathbf{n}$} & \multicolumn{4}{|c|}{ Without nose-drops } & \multicolumn{4}{|c|}{ With nose-drops } \\
\hline & & Mean & s.d. & Median & Range & Mean & s.d. & Median & Range \\
\hline 7 & 5 & 242 & 76 & 242 & $140-340$ & 302 & 52 & 321 & $225-340$ \\
\hline 8 & 18 & 262 & 56 & 265 & $150-344$ & 393 & 106 & 371 & $169-604$ \\
\hline 9 & 25 & 302 & 87 & 324 & $114-434$ & 390 & 103 & 397 & $137-582$ \\
\hline 10 & 17 & 324 & 123 & 280 & $186-638$ & 431 & 116 & 425 & $234-680$ \\
\hline 11 & 20 & 321 & 77 & 295 & $221-472$ & 423 & 129 & 402 & $262-849$ \\
\hline 12 & 20 & 285 & 94 & 268 & $158-479$ & 389 & 139 & 371 & $177-668$ \\
\hline 13 & 14 & $339^{-}$ & 69 & $3 \overline{35}$ & $197-498^{-}$ & $427^{-}$ & 91 & 425 & $-304-629$ \\
\hline
\end{tabular}

a larger nasal airway as measured with the planimeter.

A history of adenoidectomy was significantly related to a history of mouth-breathing at night $(0.01<\mathrm{P}<0.05)$ and to all the variables measured on the profile cephalogram expressing the depth of the airway space: the depth of the adenoids, the relative depth and the relative size of the adenoids $(0.001<P<0.01$ and $P<0.001)$. Children who had undergone adenoidectomy thus tended to have small adenoids and a large airway but still tended to be mouth-breathers.

A history of adenoidectomy was also negatively related to the angle OPT/HOR $(0.01<\mathrm{P}<0.05)$, so that children who had undergone adenoidectomy tended to have a small angle OPT/HOR: There was also a relation between adenoidectomy and the size of the angle s-n-sm $(0.01<\mathrm{P}<0.05)$, the mandible tending to be more retrognathic in children who had undergone adenoidectomy.

A history of rhinitis at the time of the examination was positively related to a history of mouth-breathing at night $(0.001<\mathrm{P}<0.01)$ and also related to the angle ML/VER $(0.0 .1-\mathrm{P}<0.05)$, which_was_smaller_in_children with rhinitis. There was also a relation between rhinitis and the size of the airway as judged visually on the antero-posterior cephalogram $(0.01<\mathrm{P}<0.05)$. The airway was smaller in children with rhinitis.

A history of mouth-breathing during the day was related to a history of mouth-breathing at night $(P<0.001)$ and to the variables $N L / M L$, n-sp': sp'-me and s-tgo: n-me $(0.01<\mathrm{P}<0.05)$, the angle $\mathrm{NL} / \mathrm{ML}$ as well as the lower anterior face height tending to be large in mouthbreathers.

There were significant relations between mouth-breathing at night and a history of aden- oidectomy as well as rhinitis at the time of the examination. Significant relations were also found to the size of the airway measured and judged on the antero-posterior cephalogram, to the variables s-n-sm, NSL/ML, NL/ML, s-sp': $\mathrm{sp}^{\prime}$-me, ILs/NL and ILs/ILi $(0.01<\mathrm{P}<0.05)$, as well as to the variable $\mathrm{n}$-s-gn $(0.001<\mathrm{P}<0.01)$. Mouth-breathing at night thus tended to occur in subjects with a large airway and to be associated with small angles s-n-sm and ILs/ILi but with large angles $\mathrm{NSL} / \mathrm{ML}, \mathrm{NL} / \mathrm{ML}, \mathrm{n}$-s-gn and ILs/NL. Mouth-breathing also tended to be associated with a small quotient between the upper and lower anterior face height.

\section{Correlations between rhinomanometric and other variables}

The coefficients of correlation between airflow and resistance with and without nose-drops were 0.66 .

The airflow and resistance with nose drops were significantly correlated to the index for anterior face height (rho $=0.21$ and rho $=-0.22$, respectively), which means that airflow was small (and nasal resistance great) in children with a small index for anterior face height. There was an almost significant correlation between a history of mouth-breathing at night and airflow with nose drops (rho $0.18, \mathrm{P}=0.06$ ) and resistance with nose-drops (rho $0.17, \mathrm{P}=0.08$ ).

The airflow and resistance without nose-drops were significantly correlated to the angle NL/ML (rho $=-0.19$ and rho $=0.19$, respectively). Thus, airflow tended to be small and resistance great in children with a large angle NL/ML. The resistance was also correlated to the angle RL/ML (rho $=0.18$ ), and to the index for anterior face height (rho $=-0.18$ ). The resistance without nose-drops thus tended to be great in 
Table 4 Distance pm-ad2 (in $\mathrm{mm}$ ) in children of different age

\begin{tabular}{rrrrlr}
\hline $\begin{array}{l}\text { Age } \\
\text { year }\end{array}$ & $\mathrm{n}$ & Mean & s.d. & Median & \multicolumn{1}{l}{ Range } \\
\hline 7 & 5 & 13.3 & 3.1 & 12.0 & $10.0-16.7$ \\
8 & 18 & 13.6 & 3.1 & 13.9 & $8.5-18.5$ \\
9 & 25 & 14.7 & 2.9 & 15.1 & $7.3-20.2$ \\
10 & 17 & 14.9 & 4.1 & 13.3 & $7.9-24.4$ \\
11 & 20 & 15.2 & 3.9 & 14.6 & $8.9-22.4$ \\
12 & 20 & 15.5 & 5.1 & 16.2 & $5.9-23.6$ \\
13 & 14 & 16.6 & 4.4 & 15.8 & $11.9-26.5$ \\
\hline
\end{tabular}

children with a small index for anterior face height and a large gonial angle.

Correlations between the radiographic measures of the airway space and other variables

The variables measured on the profile cephalogram describing the morphology of the nasopharynx, like the variables recorded on the postero-anterior cephalogram, were largely intercorrelated. However, only correlations between these variables and variables of a different character will be described.

Of the measurements of the airway space on the profile cephalogram, the variable pm-ad2 showed most correlations to other types of variable. There was thus a correlation between pm-ad 2 and a history of adenoidectomy. Significant positive correlations were found between pm-ad2 and s-n-sm (rho $=0.20$ ), s-tgo: n-me (rho $=0.22$ ), and n-sp': $\mathbf{s p}^{\prime}-\mathrm{me}$ (rho $=0.19$ ). Negative correlations were found to NSL/ML (rho $=-0.23$ ) and $n$-s-gn (rho $=-0.23$ ). A small value of pm-ad2 was therefore predominantly found in children with a retrognathic mandible with large inclination and with large anterior face height.

The variable pm-ad2 was also correlated to age (rho $=0.23$ ). Values for the distance pmad2 in children of different age are given in Table 4.

The size of the nasal airway measured with the planimeter on the postero-anterior radiograph was correlated to a history of allergy and mouth-breathing during the night and the semiquantitative recording of airway space to a history of rhinitis. Of the variables recorded in the postero-anterior radiograph, only the width of the nose was significantly correlated to variables of the facial morphology, namely to n-sgn (rho $=-0.19$ ).
None of the radiological variables expressing the size of the airway was significantly correlated to the rhinomanometric recordings or to the head position.

\section{Discussion}

Three methods of diagnosing mouth-breathing-history, rhinomanometry and measurement of the airway on cephalograms-were used in this study. There were no or only weak correlations between the results obtained with the three methods, however. In spite of the efforts made, using three methods, it was not possible to decide with certainty which children were mouth-breathers.

Of the radiological methods evaluation of the frontal cephalogram seems to be the least useful. The relations found between a history of allergy and mouth-breathing at night on the one hand and a large airway on the frontal cephalogram on the other are difficult to explain and illogical. The variables measuring the size of the airway on the frontal cephalogram were also, with one exception, not correlated to the facial morphology. The morphology of the nasal cavity is too complicated to make the use of a standard frontal cephalogram meaningful (Montgomery et al. 1979). Also, the largest resistance to the airflow in the nasal area is found at the isthmus of the nares (Bachmann 1982), which is not reproduced on the radiograph. This conclusion regarding the usefulness of the frontal radiograph is in line with the results of Sörensen et al. (1980), who found measurements of the airway on the profile cephalogram to correlate with the nasal resistance, which, however, was not the case for the measurement of nasal width on the frontal cephalogram.

Of the variables measuring the airway in the profile cephalogram, pm-ad2 showed most correlations to facial morphological traits known to be related to mouth-breathing. The variable pm-ad 2 was, however, not correlated to a history of mouth-breathing or to the rhinomanometric determination of the airflow through the nose. There was also only a tendency to a correlation between the rhinomanometric recordings of the airflow and a history of mouthbreathing.

Mouth-breathing has in numerous studies been found to be related to a special facial type (Bushey 1979, Linder-Aronson 1979, Han- 
nuksela 1981, Bresolin et al. 1983, Solow et al. 1984), mouth-breathing children having a retrognathic mandible, a large anterior face height (especially lower face height) and a steep mandibular inclination (long-face morphology). In the present study, a history of mouth-breathing and the variable pm-ad 2 in particular, but also the rhinomanometric recordings of the airflow were correlated to cephalometric traits of long-face morphology. This may be taken as indirect evidence that these methods of diagnosing mouth-breathing are valid. A history of mouth-breathing and the radiological size of the airway (pm-ad2) are thereby at least as useful as the rhinomanometric recording of the airflow. That rhinomanometry is not superior to the other methods may be due to the relatively large error of the method (Kuster et al. 1989) and to the fact that the rhinomanometric measurement is only a momentary recording. A history of mouth-breathing, on the other hand, is based on observations over a long period in different situations of daily life.

The seemingly contradictory association between adenoidectomy and a history of mouthbreathing, so that children who had undergone adenoidectomy still tended to be mouthbreathers, may be due to the fact that in many cases the mouth-breathing was not due to adenoids but to some other still persisting factor. This is in line with the findings of LinderAronson (1973), who reported that up to 30 per cent of children who had undergone adenoidectomy were still mouth-breathers one year after the operation.

None of the methods of diagnosing mouthbreathing tried was found to be related to the variables expressing the head position or the inclination-of the cervical spine. This-is contrary to the findings of other authors (Linder-Aronson 1979, Solow and Greve 1979, Wenzel et al. 1983, Solow et al. 1984). The explanation may be that the method of recording head position/cervical spine inclination is in our hands, in spite of special care, too imprecise, in accordance with a previous report (Kuster et al. 1989).

We conclude from this study that diagnosis of mouth-breathing at orthodontic examination should preferably be based on different supplementary methods, the patient's history being at least as valuable as seemingly objective methods. Of the radiological methods, the simple measurement of the distance pm-ad 2 on the profile cephalogram was superior to planimetric determination of adenoid and airway sizes on the profile and frontal cephalograms.

\section{Address for correspondence}

Dr. Urs Thüer

Klinik für Kieferorthopädie

Freiburgstrasse 7

$\mathrm{CH}-3010$ Bern

Switzerland

\section{References}

Archer S Y, Vig P S 1985 Effects of head position on intraoral pressures in Class I and Class II adults. American Journal of Orthodontics 87: 311-318

Bachmann W 1982 Die Funktionsdiagnostik der behinderten Nasenatmung. Springer-Verlag Berlin

Bresolin D, Shapiro P A, Shapiro G G, Chapko M K, Dassel S 1983 Mouth breathing in allergic children: Its relationship to dentofacial development. American Journal of Orthodontics 83: $334-340$

Bushey R S 1979 Adenoid obstruction of the nasopharynx. In McNamara J A (ed) Naso-respiratory function and craniofacial growth. Monograph 9, Craniofacial Growth Series, Center for Human Growth and Development, University of Michigan, Ann Arbor

Gebauer U 1977 Elektronische Rechenanlage zur arcogrammetrischen Modelldiagnostik und zum Auswerten von Fernröntgenbildern. Schweizerische Monatsschrift für Zahnheilkunde 87: 1170-1180

Gurley W H, Vig P S 1982 A technique for the simultaneous measurement of nasal and oral respiration. American - Journal of Orthodontics 82: 33-41

Hannuksela A 1981 The effect of moderate and severe atopy on the facial skeleton. European Journal of Orthodontics 3: $187-193$

Hellsing E, L'Estrange P 1987 Changes in lip pressure following extension and flexion of the head and at changed mode of breathing. American Journal of Orthodontics 91: 286-294

-Holmberg H, Linder-Aronson-S 1.979 Cephalometric radiographs as a means of evaluating the capacity of the nasal and nasopharyngeal airway. American Journal of Orthodontics 76: $479-490$

Ingervall B, Thüer U 1988 Variation of the pressure from the cheeks on the teeth and alveolar process with head position. Angle Orthodontist 58: 47-57

Keall C L, Vig P S 1987 An improved technique for the simultaneous measurement of nasal and oral respiration. American Journal of Orthodontics 91: 207-212

Kuster R, Thüer U, Ingervall B 1988 Reproduzierbarkeit rhinomanometrischer Messungen des Nasenatmungswiderstands und roentgenkephalometrische Registrierungen der natürlichen Kopfhaltung bei Kindern. Fortschritte der Kieferorthopädie 50: 43-53

Linder-Aronson S 1970 Adenoids. Their effect on mode of breathing and nasal airflow and their relationship to 
characteristics of the facial skeleton and the dentition. Acta Oto-Laryngologica, Suppl. 265

Linder-Aronson S 1973 Effects of adenoidectomy on mode of breathing, size of adenoids and nasal airflow. Journal for Oto-Rhino-Laryngology 35: 283-302

Linder-Aronson S 1979 Naso-respiratory function and craniofacial growth. In McNamara J A (ed) Nasorespiratory function and craniofacial growth. Monograph 9, Craniofacial Growth series, Center for Human Growth and Development, University of Michigan, Ann Arbor

Linder-Aronson S, Henrikson C O 1973 Radiocephalometric analysis of antero-posterior nasopharyngeal dimensions in 6- to 12-year-old mouth breathers compared to nose breathers. Journal for Oto-Rhino-Laryngology 35: 19-29

Montgomery W M, Vig P S, Staab E V, Matteson S R 1979 Computed tomography: A three-dimensional study of the nasal airway. American Journal of Orthodontics 76: 363375

Pearson E S, Hartley H O 1966 Biometrica tables for statisticians. Vol. 1 (3rd ed). Cambridge University Press

Siersbaek-Nielsen S, Solow B 1982 Intra- and interexaminer variability in head posture recorded by dental auxiliaries. American Journal of Orthodontics 82: 50-57

Solow B, Kreiborg S 1977 Soft-tissue stretching: a possible control factor in craniofacial morphogenesis. Scandinavian Journal of Dental Research 85: 505-507

Solow B, Greve E 1979 Craniocervical angulation and nasal respiratory resistance. In McNamara J A (ed)
Nasorespiratory function and craniofacial growth. Monograph 9, Craniofacial Growth series, Center for Human Growth and Development, University of Michigan, Ann Arbor

Solow B, Greve E 1980 Rhinomanometric recording in children. Rhinology 18: 31-42

Solow B, Siersbaek-Nielsen S, Greve E 1984 Airway adequacy, head posture, and craniofacial morphology. American Journal of Orthodontics 86: 214-223

Sörensen H, Solow B, Greve E 1980 Assessment of the nasopharyngeal airway. Acta Otolaryngologica 89: 227232

Vig P S, Hall D J 1980 The inadequacy of cephalometric radiographs for air-way assessment (letter). American Journal of Orthodontics 77: 230-232

Warren D W, Hinton V A, Hairfield W M 1986 Measurement of nasal and oral respiration using inductive plethysmography. American Journal of Orthodontics 89: 480-484

Wenzel A, Henriksen J, Melsen B 1983 Nasal respiratory resistance and head posture: Effect of internasal corticosteroid (Budesonide) in children with asthma and perennial rhinitis. American Journal of Orthodontics 84: 422 426

Woodside D G, Linder-Aronson S 1979 The channelization of upper and lower anterior face heights compared to population standard in males between ages 6 to 20 years. European Journal of Orthodontics 1: $25-40$ 